\title{
An Immunochip-based interrogation of scleroderma susceptibility variants identifies a novel association at DNASE1L3
}

Jane Zochling ${ }^{1}$, Felicity Newell ${ }^{2}$, Jac C Charlesworth ${ }^{1}$, Paul Leo ${ }^{2}$, Jim Stankovich ${ }^{1}$, Adrian Cortes ${ }^{2}$, Yuan Zhou', Wendy Stevens ${ }^{3}$, Joanne Sahhar ${ }^{4}$, Janet Roddy ${ }^{5}$, Peter Nash ${ }^{6}$, Kathleen Tymms ${ }^{7}$, Maureen Rischmueller ${ }^{8}$, Sue Lester ${ }^{8}$, Susanna Proudman ${ }^{9}$ and Matthew A Brown ${ }^{2^{*}}$

\begin{abstract}
Introduction: The aim of the study was to interrogate the genetic architecture and autoimmune pleiotropy of scleroderma susceptibility in the Australian population.

Methods: We genotyped individuals from a well-characterized cohort of Australian scleroderma patients with the Immunochip, a custom array enriched for single nucleotide polymorphisms (SNPs) at immune loci. Controls were taken from the 1958 British Birth Cohort. After data cleaning and adjusting for population stratification the final dataset consisted of 486 cases, 4,458 controls and 146,525 SNPs. Association analyses were conducted using logistic regression in PLINK. A replication study was performed using 833 cases and 1,938 controls.

Results: A total of eight loci with suggestive association $\left(P<10^{-4.5}\right)$ were identified, of which five showed significant association in the replication cohort (HLA-DRB1, DNASE1L3, STAT4, TNPO3-IRF5 and VCAM1). The most notable findings were at the DNASE1L3 locus, previously associated with systemic lupus erythematosus, and VCAM1, a locus not previously associated with human disease. This study identified a likely functional variant influencing scleroderma susceptibility at the DNASE1L3 locus; a missense polymorphism rs35677470 in DNASE1L3, with an odds ratio of $2.35\left(P=2.3 \times 10^{-10}\right)$ in anti-centromere antibody (ACA) positive cases.
\end{abstract}

Conclusions: This pilot study has confirmed previously reported scleroderma associations, revealed further genetic overlap between scleroderma and systemic lupus erythematosus, and identified a putative novel scleroderma susceptibility locus.

\section{Introduction}

Systemic sclerosis (SSc) or scleroderma is a multisystem, autoimmune disorder characterised by progressive vascular, inflammatory and fibrotic dysfunction. Skin and visceral complications of cardiac, pulmonary, gastrointestinal, muscle and renal disease can have devastating effects on quality of life and life expectancy [1].

Scleroderma has a well-established genetic component [2-4]. Most of the identified SSc susceptibility loci overlap with those of other autoimmune diseases, in particular the rheumatic disorders such as rheumatoid arthritis

\footnotetext{
* Correspondence: Matt.Brown@uq.edu.au

${ }^{2}$ University of Queensland Diamantina Institute, Translational Research Institute, Princess Alexandra Hospital, 37 Kent Street, Woolloongabba, Brisbane, QLD 4102, Australia

Full list of author information is available at the end of the article
}

and systemic lupus erythematosus (SLE) [5]. For example, Carmona et al. recently confirmed an association between SSc and the SLE risk haplotype at the IRF5 locus [6] and Martin et al. recently performed a pan-meta-analysis of SSc and SLE to look at the susceptibility overlap between the two diseases [7]. Using 6,835 cases and 14,274 controls they identified a novel pleiotropic locus at KIAA0319L on chromosome 1 and identified two SLE loci (near PXK and $J A Z F 1$ ) that also contribute to SSc [7].

To identify further susceptibility loci and to explore the genetic overlap with other antibody-mediated immune diseases, we undertook an SSc association study using the Immunochip, a custom array including SNPs of interest in a wide variety of autoimmune disorders [8]. A replication study was then performed using previously published case 
data from a genome-wide association study (GWAS) of scleroderma [9], and control data from a GWAS of bone density variation [10].

\section{Methods \\ Samples}

We selected 532 cases for genotyping from the Australian Scleroderma Cohort Study (ASCS) [11]; a prospective study of risk factors for clinically important outcomes in SSc. They fulfilled either the American College of Rheumatology (ACR) criteria for classification of SSc [12] or the Medsger criteria for limited SSc (to enable broad representation of the disease spectrum) [13]. The study was approved by the Human Research Ethics Committee (Tasmanian) Network and human research ethics committees of St. Vincent's Hospital and Monash Medical Centre, Melbourne, VIC; Sunshine Coast Rheumatology, Maroochydore, QLD; Royal Adelaide Hospital, Adelaide, SA; St George Hospital, Sydney, NSW; Royal Perth Hospital, Perth, WA; and Prince Charles Hospital, Brisbane, QLD. All patients gave written, informed consent.

\section{Genotyping}

Cases were genotyped with the Immunochip, an Illumina Infinium SNP microarray (Illumina Inc., San Diego, CA, USA) [8], at the University of Queensland Diamantina Institute, Brisbane, QLD, Australia. The Immunochip contains 195,806 common and rare SNPs of interest in a wide variety of autoimmune disorders. Control genotypes were obtained from 4,537 samples from the 1958 British Birth Cohort [14]. Genotypes were called using the Illumina GenTrain clustering algorithm. Cases and controls were clustered separately.

For replication purposes, genotypes from 833 SSc cases were obtained from dbGAP (dbGaP Study Accession: phs000357.v1.p1) [9,15]. These samples were genotyped with the Illumina Human610-Quad v1.0 BeadChip. Control genotypes were obtained from 1,938 subjects of white British ancestry genotyped as part of the Anglo-Australasian Osteoporosis Genetics Consortium program using either Illumina Infinium II HumHap300 or $370 \mathrm{CNV}$ chips [10].

\section{Statistical analyses}

Genotype data were analysed with PLINK [16] and R [17]. There were no duplicate or closely related cases. Case $(n=2)$ and control $(n=3)$ samples with call rates less than $90 \%$ were excluded. SNPs were excluded based on Hardy-Weinberg disequilibrium $\left(P<10^{-6}\right)$, call rates less than $90 \%$, fewer than two occurrences of the minor allele, and significantly different rates of missingness $\left(P<10^{-4}\right)$ between cases and controls. Eigenstrat [18] was run on a pruned SNP set with default settings to exclude population ancestry outliers and ensure cases and controls were ethnically matched. Subjects lying more than six standard deviations from the mean of any principal component were excluded (Immunochip set 44 cases and 76 controls excluded; replication set 129 cases and 31 controls excluded).

Four-digit classical MHC allele dosages at $H L A-A$, HLA-B, HLA-C, HLA-DRB1, HLA-DQA1 and HLA-DQB1 were imputed using HLA*IMP $[19,20]$ in the Immunochip dataset, and tested for association.

Logistic regression was used for all association analyses using principal components derived from the Eigenstrat analysis as covariates to control for population stratification. A single principal component was used for the Immunochip analysis and two principal components for the replication dataset; including further principal components for either set did not reduce the genomic inflation factor further. A negative control set of 2,805 SNPs outside the major histocompatibility complex (MHC), associated with reading and learning, schizophrenia and psychosis [19], was used to estimate the genomic inflation factor and calculate adjusted $P$ values. Genotype intensity cluster plots were manually examined for all suggestive associations with unadjusted $P$ values less than $10^{-4.5}$, a threshold used in previous GWAS [21]. To test for secondary association signals at each locus, genotypes at the most significant variant were added to the logistic regression model as a covariate, and all other variants at the locus were tested. To correct secondary analyses for multiple testing, we estimated the effective number of independent tests at loci using the eigenvalues of the matrix of correlations between SNPs [22], as implemented in SNPSpD [23].

For variants associated with SSc at the nominally suggestive threshold $\left(P<10^{-4.5}\right)$, we also tested for differences in allele frequencies between patients with different disease subtypes and MHC genotypes.

For replication, cases and controls genotypes were imputed as implemented in IMPUTE2 [24] with the use of the merged 1000 Genomes and UK10K reference dataset. All SNPs we were attempting to replicate had an info score of $>0.7$. Meta-analysis was performed using METAL weighted by inverse variance [25]. Power was calculated using the Genetic Power Calculator [26].

\section{Results}

After sample and SNP exclusions, in the Immunochip dataset genotypes were analysed at 145,921 autosomal SNPs in 486 cases and 4,458 controls, with a genomic inflation factor of 1.02 (Q-Q plot, Figure S1 in Additional file 1). Eighty-six percent of the cases were female, mean age was 60 years and mean disease duration 14 years. Twenty-five percent of cases had diffuse disease, $72 \%$ limited pattern, and 3\% were intermediate; $43 \%$ were anticentromere antibody (ACA) positive and 15\% anti-Scl-70 antibody positive. Considering the replication set, 700 scleroderma cases and 1,899 controls remained after 
quality control. Of the replication cases, $36 \%$ had diffuse disease, 64\% limited pattern; 32\% were ACA positive. The genomic inflation factor for the replication set was 1.045. The Immunochip study has $80 \%$ power to detect associations at $P<10^{-4.5}$ for a variant with minor allele frequency (MAF) of 0.3 with $\mathrm{D}^{\prime}=0.8$ with a SNP with heterozygote odds ratio (OR) of 1.65 .

We detected suggestive associations in the Immunochip data (uncorrected $P<10^{-4.5}$ ) at eight loci (Table 1), five of which showed association in the replication cohort (HLADRB1, DNASE1L3, STAT4, TNPO3-IRF5, and VCAM1) (Table 1, Manhattan plot Figure 1). There was also evidence of association at the previously reported genomewide significant CD247 SNP [9] (rs2056626, OR =0.76, $\left.P=1.1 \times 10^{-4}\right)$, but no evidence of association at the genome-wide significant TNIP1 locus [27] (rs2233287, $P=0.94)$. The overlap between previously reported genome-wide significant SSc loci (outside the MHC) and our data, at an unadjusted $P<0.01$, is shown in Table 2 . Not all previously associated SSc loci could be investigated owing to the limitations of markers available on the array.

The strongest SNP association (Table 1) was with rs2857130 in the MHC. Testing imputed MHC alleles for association, the strongest signal was for $D R B 1 * 11: 04$ (Table 3). There was also a protective association with $D R B 1 * 07: 01$, but no other alleles or SNPs showed evidence of association after conditioning on these two. In particular, there was little evidence of association with the rare $D R B 1 * 11: 03$ allele, which only differs from $D R B 1 * 11: 04$ at one site encoding part of a hypervariable, peptide-binding region (R71E; OR 1.46, $P=0.35$ ), and a model with $D R B 1 * 11: 03$ and $D R B 1 * 11: 04$ dosage combined does not fit as well as a model with $D R B 1 * 11: 04$ dosage alone.

Consistent with previous findings, $D R B 1 * 11: 04$ is a particularly strong risk factor for Scl70-positive SSc [28] (Table 3). However, compared to controls the frequency of this allele is also elevated in ACA-positive cases and in cases negative for both antibodies. The protective effect of $D R B 1 * 07: 01$ is strongest against ACA-positive disease, and there was no evidence that this allele protects against anti-Scl70 antibody-positive disease.

The most significant STAT4 locus association was at the SNP rs13426947 (Table 1). This was one of 15 associated intronic SNPs in STAT4 $\left(P<3 \times 10^{-4}\right)$, all correlated with $\operatorname{rs} 13426947\left(r^{2}>0.55\right.$, MAF 0.19 to 0.26$)$. These included the top-ranked SNP at this locus from a previous SSc GWAS (rs3821236, $P=2.6 \times 10^{-5}, r^{2}=0.97$ with rs13426947) [9]. No SNPs in this region were significantly associated with SSc $(P<0.01)$ after conditioning on rs13426947. rs13426947 also showed association in the replication set $\left(P=5.4 \times 10^{-3}\right)$, and in the combined analysis $\left(P=6.1 \times 10^{-7}\right)$.

At the IRF5/TNPO3 locus, there was a group of 23 associated SNPs $\left(P<5 \times 10^{-5}\right)$ highly correlated with the top-ranked SNP rs34381587 $\left(r^{2}>0.90\right.$, MAF 0.11 to $0.13)$, including the top-ranked SNP reported previously (rs10488631, $P=2.4 \times 10^{-5}, r^{2}=0.998$ with $\mathrm{rs} 34381587$ ) [9]. There was some evidence of association with a rare SNP between the two genes $(128,379,270$ base pairs,

Table 1 SNPs associated with SSc $\left(P<10^{-4.5}\right)$ in an analysis of Immunochip genotypes for 486 cases and 4,458 controls, replication cohort of 700 SSc cases ( 220 ACA positive) and 1,889 controls, and combined

\begin{tabular}{|c|c|c|c|c|c|c|c|c|c|c|}
\hline$\overline{C h r}$ & $\begin{array}{l}\text { Location range } \\
\text { (base pairs, hg18) }\end{array}$ & Best SNP & $\begin{array}{l}\text { MAF } \\
\text { cases }\end{array}$ & $\begin{array}{l}\text { MAF } \\
\text { controls }\end{array}$ & $\begin{array}{l}\text { Immunochip } \\
\text { OR }\end{array}$ & $\begin{array}{l}\text { Immunochip } \\
P \text { value }\end{array}$ & $\begin{array}{l}\text { Replication } \\
\text { OR }\end{array}$ & $\begin{array}{l}\text { Replication } \\
P \text { value }\end{array}$ & $\begin{array}{l}\text { Combined } \\
\text { analysis }\end{array}$ & $\begin{array}{l}\text { Gene } \\
\text { annotation" }\end{array}$ \\
\hline 6 & $32,039,116-32,888,448$ & rs2857130 & 0.293 & 0.389 & 0.68 & $2.8 \times 10^{-7}$ & 0.81 & 0.003 & $1.3 \times 10^{-8}$ & $\begin{array}{l}\text { Intergenic } \\
\text { (HLA region) }\end{array}$ \\
\hline 1 & $101,009,225$ & Novel SNP & 0.024 & 0.008 & 3.31 & $1.8 \times 10^{-6}$ & 2.49 & 0.031 & $1.9 \times 10^{-7}$ & $\begin{array}{l}\text { Intergenic } \\
(\text { VCAM1) }\end{array}$ \\
\hline 3 & $58,158,676-58,289,303$ & rs35677470 & 0.122 & 0.083 & 1.63 & $3.4 \times 10^{-6}$ & 1.27 & 0.027 & $1.2 \times 10^{-6}$ & $\begin{array}{l}\text { DNASE1L3 } \\
\text { (coding) }\end{array}$ \\
\hline 3 & $58,158,676-58,289,303$ & rs35677470 & 0.174 & 0.083 & 2.36 & $2.3 \times 10^{-10}$ & 1.74 & $3.0 \times 10^{-4}$ & $8.71 \times 10^{-13}$ & $\begin{array}{l}\text { DNASETL3 } \\
\text { (coding) }^{\wedge}\end{array}$ \\
\hline 7 & $128,372,852-128,499,110$ & rs34381587 & 0.158 & 0.113 & 1.53 & $1.2 \times 10^{-5}$ & 1.38 & $8.7 \times 10^{-4}$ & $5.2 \times 10^{-8}$ & $\begin{array}{l}\text { IRF5/TNPO3 } \\
\text { (intron) }\end{array}$ \\
\hline 16 & $73,863,956-74,046,823$ & rs11149824 & 0.469 & 0.391 & 1.35 & $1.4 \times 10^{-5}$ & 1.054 & 0.442 & $3.2 \times 10^{-4}$ & $\begin{array}{l}\text { CFDP1 } \\
\text { (intron) }\end{array}$ \\
\hline 2 & $43,775,459-43,784,213$ & rs13403030 & 0.384 & 0.318 & 1.36 & $1.5 \times 10^{-5}$ & 0.92 & 0.242 & 0.027 & $\begin{array}{l}\text { PLEKHH2 } \\
\text { (intron) }\end{array}$ \\
\hline 2 & $191,608,694-191,641,499$ & rs13426947 & 0.253 & 0.191 & 1.42 & $1.8 \times 10^{-5}$ & 1.25 & $5.4 \times 10^{-3}$ & $6.1 \times 10^{-7}$ & STAT4 (intron) \\
\hline 1 & $61,883,642$ & rs 2886326 & 0.249 & 0.195 & 1.41 & $2.0 \times 10^{-5}$ & 0.96 & 0.606 & $7.4 \times 10^{-3}$ & $\begin{array}{l}\text { Intergenic } \\
\text { (TM2D1) }\end{array}$ \\
\hline
\end{tabular}

\#Gene annotation is based on the location of the most significant SNP; ${ }^{\wedge}$ ACA-positive cases only. SNP, single nucleotide polymorphism; SSc, systemic sclerosis; $\mathrm{ACA}$, anti-centromere antibody; Chr, chromosome; MAF, minor allele frequency; OR, odds ratio. 


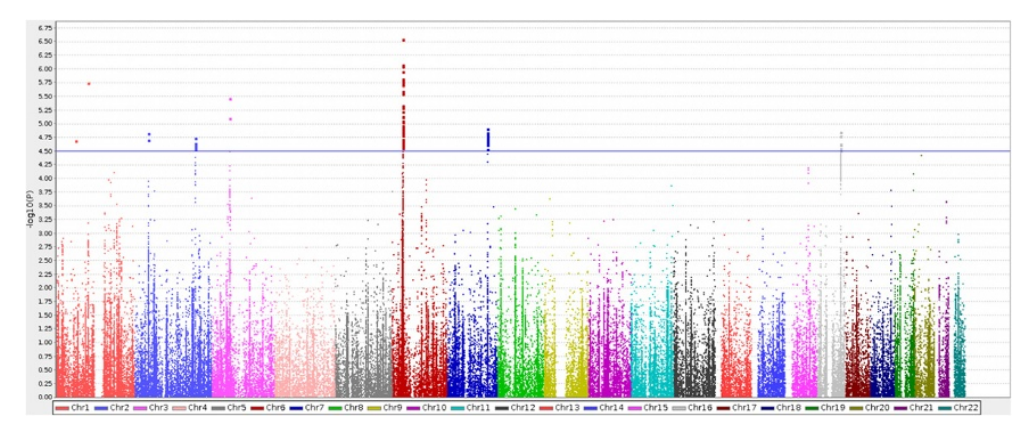

Figure 1 Manhattan Plot for association study finding from Immunochip genotyped cases and controls.

MAF 0.028 , OR $1.83, P=6.0 \times 10^{-4} ; P=0.05$ after correction for the 83 independent tests). rs34381587 also showed association in the replication set $\left(P=8.7 \times 10^{-4}\right)$, and near genome-wide significance in the combined analysis $(P=$ $\left.5.2 \times 10^{-8}\right)$.

Association was observed and replicated at chromosome 3p14, spanning DNASE1L3 to AXOX2 (including $P X K$; Figure 2), a region that has previously been associated with both SLE [29] and SSc [7]. While the peak association with SLE was originally identified at an intronic SNP rs6445975 in PXK (a PX domain containing serine/threonine kinase), the strongest association with SSc on the Immunochip was at a missense SNP rs35677470 (R206C) in DNASE1L3 (deoxyribonuclease I-like 3); $187 \mathrm{~kb}$ distal of rs6445975. Linkage disequilibrium between the two SNPs is modest $\left(r^{2}=0.13\right)$, and there is weak evidence of a secondary association with rs6445975 in our data after conditioning on $\mathrm{rs} 35677470(\mathrm{OR}=1.19$, $P=0.03$ ). No other associations at this locus are significant after correction for multiple testing. The association with rs35677470 is confined to ACA-positive cases (estimated OR 2.36, $\left.P=2.3 \times 10^{-10}\right)$, with no association in ACAnegative cases $(P=0.76)$. rs35677470 also showed association in the replication set $(P=0.027)$, and in the combined analysis $\left(P=1.2 \times 10^{-6}\right)$. As in the Immunochip analysis, in the replication set association was much stronger in the ACA-positive group $\left(P=3.0 \times 10^{-4}\right)$, and overall $(P=$ $\left.8.71 \times 10^{-13}\right)$. Association was particularly significant in limited scleroderma $\left(P=3.36 \times 10^{-9}\right.$ in overall dataset $)$ compared with diffuse scleroderma $(P=0.57)$, consistent with the association of ACA antibody status with limited disease. The non-synonymous DNASE1L3 variant is predicted to be deleterious to the protein product using in silico functional prediction tools including both SIFT [30] and PolyPhen [31]. Apart from the DNASE1L3 locus, no other associations showed evidence of heterogeneity by antibody status, or between limited and diffuse SSc.

A novel intergenic SNP in VCAM1 achieved suggestive association with SSc overall in Immunochip cases (OR = 3.31, $\left.P=1.8 \times 10^{-6}\right)$. Association was seen with both limited $\left(P=1.8 \times 10^{-4}\right)$, and diffuse disease $\left(8.9 \times 10^{-5}\right)$. The findings for overall and limited disease were supported in the replication dataset $\left(P=0.031\right.$ and $3.1 \times 10^{-3}$ respectively) but not with diffuse disease $(P=0.7)$. A combined meta-analysis gave $P$ values of $1.9 \times 10^{-7}$ for all cases, $1.9 \times$ $10^{-6}$ for limited and $4.3 \times 10^{-4}$ for diffuse disease.

\section{Discussion}

The major novel finding of this study is the significant association of a functional SNP (rs35677470) in DNASE1L3

Table 2 Association finding for previously reported loci achieving $P<0.01$ in Immunochip, with findings in replication and overall datasets

\begin{tabular}{|c|c|c|c|c|c|c|c|c|c|c|c|}
\hline SNP & $\mathrm{Chr}$ & $\begin{array}{l}\text { Location } \\
\text { (hg18; bp) }\end{array}$ & Locus & MAF cases & $\begin{array}{l}\text { MAF } \\
\text { controls }\end{array}$ & OR & $\begin{array}{l}\text { Unadjusted } \\
P \text { value }\end{array}$ & Replication OR & $\begin{array}{l}\text { Replication } \\
P \text { value }\end{array}$ & $\begin{array}{l}\text { Combined } \\
\text { analysis }\end{array}$ & References \\
\hline rs2056626 & 1 & $165,687,049$ & CD247 & 0.359 & 0.428 & 0.76 & $1.1 \times 10^{-4}$ & 0.84 & 0.007 & $3.9 \times 10^{-6}$ & {$[6,7,11]$} \\
\hline rs3821236 & 2 & $191,611,003$ & STAT4 & 0.255 & 0.194 & 1.41 & $2.6 \times 10^{-5}$ & 1.24 & 0.008 & $1.2 \times 10^{-6}$ & {$[6,7]$} \\
\hline rs10168266 & 2 & $191,644,049$ & STAT4 & 0.249 & 0.190 & 1.40 & $4.1 \times 10^{-5}$ & 1.30 & 0.001 & $1.9 \times 10^{-7}$ & [11] \\
\hline rs7574865 & 2 & $191,672,878$ & STAT4 & 0.286 & 0.225 & 1.35 & $1.2 \times 10^{-4}$ & 1.15 & 0.066 & $5.7 \times 10^{-5}$ & [7] \\
\hline rs2176082 & 3 & $58,306,226$ & PXK & 0.343 & 0.296 & 1.31 & $2.6 \times 10^{-4}$ & 1.15 & 0.046 & $7.2 \times 10^{-5}$ & [16] \\
\hline rs 4728142 & 7 & $128,361,203$ & TNP03-IRF5 & 0.497 & 0.449 & 1.23 & $3.2 \times 10^{-3}$ & 1.23 & 0.002 & $2.1 \times 10^{-5}$ & {$[6,11]$} \\
\hline rs10488631 & 7 & $128,381,419$ & TNP03-IRF5 & 0.156 & 0.114 & 1.50 & $2.4 \times 10^{-5}$ & 1.36 & 0.001 & $1.6 \times 10^{-7}$ & {$[6,7,11]$} \\
\hline rs12531711 & 7 & $128,404,702$ & TNP03-IRF5 & 0.156 & 0.113 & 1.51 & $2.1 \times 10^{-5}$ & 1.38 & 0.001 & $8.6 \times 10^{-8}$ & [11] \\
\hline rs1378942 & 15 & $72,864,420$ & CSK & 0.379 & 0.319 & 1.27 & $8.7 \times 10^{-4}$ & 1.17 & 0.023 & $7.8 \times 10^{-5}$ & [11] \\
\hline
\end{tabular}

Chr chromosome; bp, base pairs; MAF, minor allele frequency; OR, odds ratio. 
Table 3 Association testing results for MHC alleles DRB1*11:04 and DRB1*07:01

\begin{tabular}{|c|c|c|c|c|c|c|}
\hline \multirow[b]{2}{*}{ Group } & \multicolumn{3}{|c|}{ Results for DRB1*11:04 } & \multicolumn{3}{|l|}{ Results for $D R B 1 * 07: 01$} \\
\hline & Mean allele dosage & OR $(95 \% \mathrm{Cl})$ & $P$ value & Mean allele dosage & OR $(95 \% \mathrm{Cl})$ & $P$ value \\
\hline Controls $(n=4458)$ & 0.037 & 1 (ref) & & 0.287 & 1 (ref) & \\
\hline Cases $(n=486)$ & 0.105 & $3.07(2.00-4.71)$ & $2.8 \times 10^{-7}$ & 0.167 & $0.58(0.46-0.74)$ & $1.4 \times 10^{-5}$ \\
\hline ACA-positive ( $44 \%$ of cases) & 0.080 & $2.46(1.28-4.73)$ & & 0.105 & $0.34(0.22-0.53)$ & \\
\hline ACA-negative ( $56 \%$ of cases) & 0.118 & $3.62(2.13-6.16)$ & $0.19^{*}$ & 0.213 & $0.79(0.59-1.07)$ & $0.002^{*}$ \\
\hline Scl70-positive ( $16 \%$ of cases) & 0.174 & $8.22(3.74-18.1)$ & & 0.294 & $1.28(0.79-2.06)$ & \\
\hline Scl70-negative (84\% of cases) & 0.088 & $2.47(1.52-4.02)$ & $0.021^{*}$ & 0.145 & $0.49(0.37-0.65)$ & $0.0012^{*}$ \\
\hline ACA \& Scl70-negative ( $40 \%$ of cases) & 0.095 & $2.61(1.36-5.00)$ & & 0.144 & $0.66(0.46-0.96)$ & \\
\hline
\end{tabular}

"These $P$ values are tests of heterogeneity, comparing allele dosages in cases positive and negative for the two antibodies. Mean dosage $=$ mean expected number of copies of alleles carried by individuals in group. OR (odds ratio) = increase in odds of being a case for each 1-unit increase in allele dosage. MHC, major histocompatibility complex; $\mathrm{Cl}$, confidence interval; ACA, anti-centromere antibody.

with ACA-positive SSc $\left(P=2.3 \times 10^{-10}\right)$. This locus has been previously reported in a SLE GWAS [29] and metaanalysis [32], however the peak associations were reported for SNPs in the nearby gene PXK. While the PXK and DNASE1L3 associations may be independent, no SNPs on the Illumina HumanHap300 chip used in the SLE GWAS are good tags for the missense SNP in DNASE1L3 (maximum $\mathrm{r}^{2}$ of 0.21 ). More recently, a functional variant in DNASE1L3 was implicated in a familial form of SLE [33], and a pan-meta-analysis of SLE and SSc also confirmed the locus near $P X K$, but in particular for ACA-positive SSc (rs2176082 [7]; $P=1.4 \times 10^{-4}$ in our data) strengthening the evidence that this locus plays a role in both diseases. These findings were independently identified in a study published whilst the current manuscript was in review [34].

The associated missense DNASE1L3 variant in our data, (rs35677470 encoding R206C) affects a highly conserved residue and there is very strong evidence that this results in loss of function of the protein [35]. DNASE1L3 encodes a member of the DNase family and functions as an endonuclease capable of cleaving DNA, mediating the breakdown of DNA during apoptosis. Al-Mayouf et al. [33] hypothesised that, in the context of SLE, dysfunction of this gene may lead to impaired DNA breakdown and clearance from apoptotic cells, resulting in the formation of self-directed DNA-specific antibodies and immune complexes. Since the same kinds of DNA-driven immune complexes (such as anti-nuclear and ACA antibodies) are also characteristic of SSc, this hypothesis is also applicable.

Suggestive association was also observed between a novel SNP in VCAM1 and overall scleroderma and in limited disease cases, both of which were also associated in the replication dataset. VCAM1 has not previously been reported to be associated with scleroderma or SLE. VCAM-1 is a member of the Ig superfamily and encodes a cell surface sialoglycoprotein expressed by cytokine-activated endothelium. It mediates leukocyte-endothelial cell adhesion and

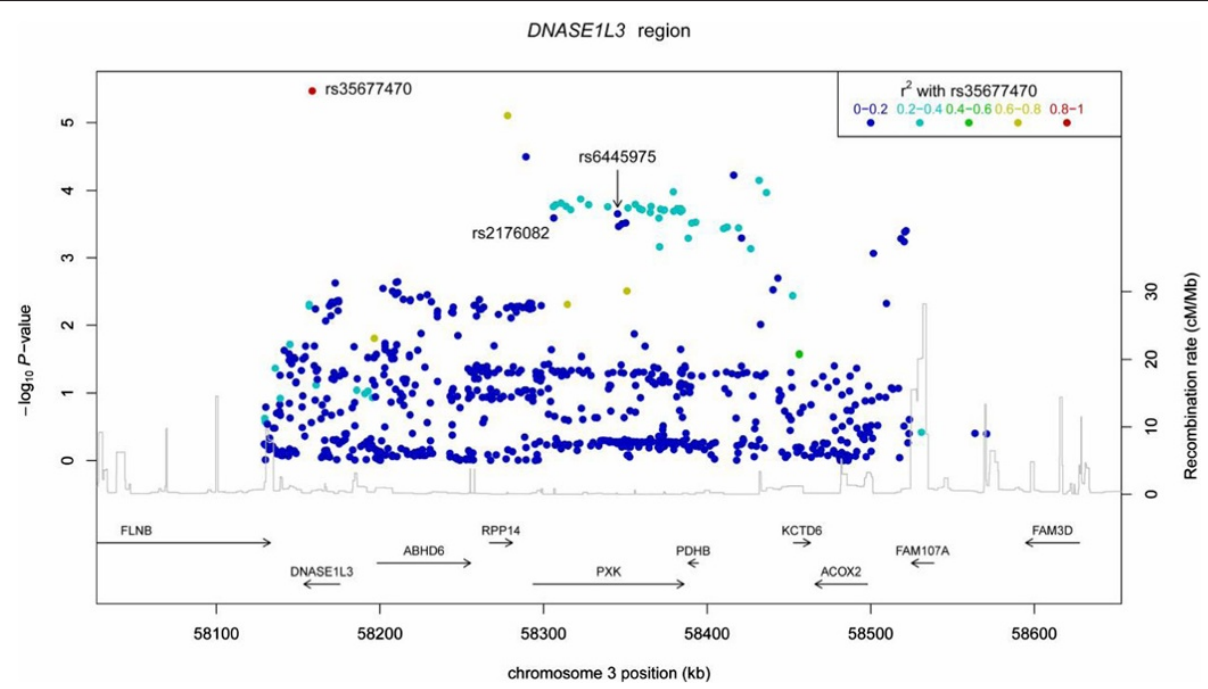

Figure 2 Locus zoom plot of chromosome 3p14 region associated with scleroderma. 
signal transduction. VCAM-1 levels have previously been shown to be elevated in early, inflammatory-phase scleroderma [36] and in limited scleroderma [37].

There were no stand-out functional variants at the STAT4 and IRF5/TNPO3 loci. These associations included many highly correlated SNPs, indicating that larger sample sizes and/or functional studies will be needed to understand and dissect these associations. It would, however, be prudent to investigate any functional variation at these loci identified in related autoimmune diseases, particularly SLE. The other novel associations are merely suggestive and require confirmation in additional datasets.

\section{Conclusions}

There is a significant association of a functional SNP in DNASE1L3 with anti-centromere antibody-positive SSc, previously reported in SLE. There is strong evidence for a loss of function of the protein. A novel association was also observed and replicated with an intergenic SNP in VCAM1.

This study serves to highlight that, even with a small but well-characterised disease cohort, significant associations can be obtained by tools such as the Immunochip, which are targeted towards analysis of disease-relevant and occasionally functional variation.

\section{Additional file}

Additional file 1: Figure S1. Q-Q plot considering reading and learning disability, psychosis and schizophrenia SNPs, excluding the MHC.

\section{Abbreviations}

ACA: anti-centromere antibody; bp: base pair; Chr: chromosome; $\mathrm{Cl}$ : confidence interval; GWAS: genome-wide association study; MAF: minor allele frequency; MHC: major histocompatibility complex; OR: odds ratio; SLE: systemic lupus erythematosus; SNP: single nucleotide polymorphism; SSc: systemic sclerosis.

\section{Competing interests}

The authors declare that they have no competing interests. There was no financial support or other benefits from commercial sources for the work reported on in the manuscript that could create a potential conflict of interest or the appearance of a conflict of interest with regard to the work.

\section{Authors' contributions \\ $J Z$ participated in the design of the study, provided patient data for the analysis and helped to draft the manuscript. FN, JC and PL performed the statistical analysis and helped to draft the manuscript. JSt, AC and YZ assisted in performing the statistical analysis. WS, JSa, JR, PN, KT and MR participated in the design of the study and provided patient data for the analysis. SL assisted in study design and performed the DNA extraction. SP participated in the design of the study and provided patient data for the analysis. MB participated in the design and coordination of the study, assisted in the genotyping, provided expert advice regarding the statistical analysis, and drafted the manuscript. All authors assisted in data interpretation, and read and approved the final manuscript.}

\section{Acknowledgments}

The Wellcome Trust Case Control Consortium, Australian Scleroderma Interest Group, Actelion Australia, Bayer, CSL Biotherapies, GlaxoSmithKline Australia, Pfizer, NHMRC Program Grant 569938 and the Australian Cancer
Research Foundation - Tasmanian Inherited Cancer Centre Computing Facility. MB was supported by an NHMRC Senior Principal Research Fellowship APP1024879.

The data used for the replication analyses described in this paper were obtained from the database of Genotypes and Phenotypes (dbGaP), at http://www.ncbi.nlm.nih.gov/gap. Genotype and phenotype data for the genome-wide association study in systemic sclerosis study (dbGaP accession number phs0 $00357 . v 1 . p 1$ ) were provided by Maureen D. Mayes, University of Texas genome-wide association study in systemic sclerosis Page 5 of 7 Health Science Center, Houston, Texas. Funding support for the original study was provided by the National Institutes of Health, and by other sources detailed in Nat Genet 2010 May; 42: 426-9. Genome-wide association study of systemic sclerosis identifies CD247 as a new susceptibility locus. Radstake TR, Gorlova O, Rueda B, Martin JE, Alizadeh BZ, Palomino-Morales R, Coenen MJ, Vonk MC, Voskuyl AE, Schuerwegh AJ, Broen JC, van Riel PL, van 't Slot R, Italiaander A, Ophoff RA, Riemekasten G, Hunzelmann N, Simeon CP, OrtegoCenteno N, González-Gay MA, González-Escribano MF; Spanish Scleroderma Group, Airo P, van Laar J, Herrick A, Worthington J, Hesselstrand R, Smith V, de Keyser F, Houssiau F, Chee MM, Madhok R, Shiels P, Westhovens R, Kreuter A, Kiener H, de Baere E, Witte T, Padykov L, Klareskog L, Beretta L, Scorza R, Lie BA, Hoffmann-Vold AM, Carreira P, Varga J, Hinchcliff M, Gregersen PK, Lee AT, Ying J, Han Y, Weng SF, Amos Cl, Wigley FM, Hummers L, Nelson JL, Agarwal SK, Assassi S, Gourh P, Tan FK, Koeleman BP, Arnett FC, Martin J, Mayes MD.

\section{Author details}

${ }^{1}$ Menzies Research Institute Tasmania, University of Tasmania, 17 Liverpool Street, Hobart, TAS 7000, Australia. ${ }^{2}$ University of Queensland Diamantina Institute, Translational Research Institute, Princess Alexandra Hospital, 37 Kent Street, Woolloongabba, Brisbane, QLD 4102, Australia. ${ }^{3}$ Rheumatology Department, St Vincent's Hospital, 41 Victoria Parade, Fitzroy, Melbourne, VIC 3065, Australia. ${ }^{4}$ Department of Rheumatology, Monash Medical Centre, 246 Clayton Road, Clayton, Melbourne, VIC 3168, Australia. ${ }^{5}$ Department of Rheumatology, Royal Perth Hospital, 197 Wellington Street, Perth, WA 6000, Australia. ${ }^{6}$ Research Unit, Sunshine Coast Rheumatology, Denna Street, Maroochydore, QLD 4558, Australia. ${ }^{7}$ Canberra Rheumatology, 40 Marcus Clarke Street, Canberra, ACT 2601, Australia. ${ }^{8}$ Department of Rheumatology, The Queen Elizabeth Hospital, 28 Woodville Road, Woodville, SA 5011, Australia. ${ }^{9}$ Rheumatology Unit, Royal Adelaide Hospital, North Terrace, Adelaide, SA 5000, Australia.

Received: 29 October 2013 Accepted: 26 August 2014

Published online: 21 October 2014

\section{References}

1. Steen VD, Medsger TA Jr: Severe organ involvement in systemic sclerosis with diffuse scleroderma. Arthritis Rheum 2000, 43:2437-2444.

2. Romano E, Manetti M, Guiducci S, Ceccarelli C, Allanore Y, Matucci-Cerinic M: The genetics of systemic sclerosis: an update. Clin Exp Rheumatol 2011, 29:S75-S86.

3. Englert H, Small-McMahon J, Chambers P, O'Connor H, Davis K, Manolios N, White $R$, Dracos $G$, Brooks P: Familial risk estimation in systemic sclerosis. Aust N Z J Med 1999, 29:36-41.

4. Arnett FC, Cho M, Chatterjee S, Aguilar MB, Reveille JD, Mayes MD: Familial occurrence frequencies and relative risks for systemic sclerosis (scleroderma) in three United States cohorts. Arthritis Rheum 2001, 44:1359-1362.

5. Martin JE, Bossini-Castillo L, Martin J: Unraveling the genetic component of systemic sclerosis. Hum Genet 2012, 131:1023-1037.

6. Carmona FD, Martin JE, Beretta L, Simeon CP, Carreira PE, Callejas JL, Fernandez-Castro M, Saez-Comet L, Beltran E, Camps MT, Egurbide MV, Airo P, Scorza R, Lunardi C, Hunzelmann N, Riemekasten G, Witte T, Kreuter A, Distler JH, Madhok R, Shiels P, van Laar JM, Fonseca C, Denton C, Herrick A, Worthington J, Schuerwegh AJ, Vonk MC, Voskuyl AE, Radstake TR, et al: The systemic lupus erythematosus IRF5 risk haplotype is associated with systemic sclerosis. PLoS One 2013, 8:e54419.

7. Martin JE, Assassi S, Diaz-Gallo LM, Broen JC, Simeon CP, Castellvi I, VicenteRabaneda E, Fonollosa V, Ortego-Centeno N, Gonzalez-Gay MA, Espinosa G, Carreira P, Spanish Scleroderma Group; SLEGEN consortium; U.S. Scleroderma GWAS group; BIOLUPUS, Camps M, Sabio JM, D'alfonso S, Vonk MC, Voskuyl AE, Schuerwegh A, Kreuter A, Witte T, Riemekasten G, Hunzelmann N, Airo P, 
Beretta L, Scorza R, Lunardi C, Van Laar J, Chee MM, Worthington J, et al: A systemic sclerosis and systemic lupus erythematosus pan-meta-GWAS reveals new shared susceptibility loci. Hum Mol Genet 2013, 22:4021-4029.

8. Cortes A, Brown MA: Promise and pitfalls of the Immunochip. Arthritis Res Ther 2011, 13:101.

9. Radstake TR, Gorlova O, Rueda B, Martin JE, Alizadeh BZ, Palomino-Morales R, Coenen MJ, Vonk MC, Voskuyl AE, Schuerwegh AJ, Broen JC, van Riel PL, van't Slot R, Italiaander A, Ophoff RA, Riemekasten G, Hunzelmann N, Simeon CP, Ortego-Centeno N, Gonzalez-Gay MA, Gonzalez-Escribano MF Airo P, van Laar J, Herrick A, Worthington J, Hesselstrand R, Smith V DeKeyser F, Houssiau F, Chee MM, et al: Genome-wide association study of systemic sclerosis identifies CD247 as a new susceptibility locus. Nat Genet 2010, 42:426-429.

10. Duncan EL, Danoy P, Kemp JP, Leo PJ, McCloskey E, Nicholson GC, Eastell R, Prince RL, Eisman JA, Jones G, Sambrook PN, Reid IR, Dennison EM, Wark J, Richards JB, Uitterlinden AG, Spector TD, Esapa C, Cox RD, Brown SD Thakker RV, Addison KA, Bradbury LA, Center JR, Cooper C, Cremin C, Estrada K, Felsenberg D, Gluer CC, Hadler J, et al: Genome-wide association study using extreme truncate selection identifies novel genes affecting bone mineral density and fracture risk. PLOS Genet 2011, 7:e1001372.

11. Nikpour M, Hissaria P, Byron J, Sahhar J, Micallef M, Paspaliaris W, Roddy J, Nash P, Sturgess A, Proudman S, Stevens W: Prevalence, correlates and clinical usefulness of antibodies to RNA polymerase III in systemic sclerosis: a cross-sectional analysis of data from an Australian cohort. Arthritis Res Ther 2011, 13:R211.

12. Masi AT, Subcommittee for Scleroderma Criteria of the American Rheumatism Association Diagnostic and Therapeutic Criteria Committee: Preliminary criteria for the classification of systemic sclerosis (scleroderma). Arthritis Rheum 1980, 23:581-590.

13. LeRoy EC, Medsger TA Jr: Criteria for the classification of early systemic sclerosis. J Rheumatol 2001, 28:1573-1576.

14. Evans DM, Spencer CC, Pointon JJ, Su Z, Harvey D, Kochan G, Oppermann U, Dilthey A, Pirinen M, Stone MA, Appleton L, Moutsianas L, Leslie S, Wordsworth T, Kenna TJ, Karaderi T, Thomas GP, Ward MM, Weisman MH, Farrar C, Bradbury LA, Danoy P, Inman RD, Maksymowych W, Gladman D, Rahman P, Morgan A, Marzo-Ortega H, Bowness P, Gaffney K, et al: Interaction between ERAP1 and HLA-B27 in ankylosing spondylitis implicates peptide handling in the mechanism for HLA-B27 in disease susceptibility. Nat Genet 2011, 43:761-767.

15. dbGAP [http://www.ncbi.n/m.nih.gov/projects/gap/cgi-bin/study.cgi? study_id=phs000357.v1.p1]

16. Purcell S, Neale B, Todd-Brown K, Thomas L, Ferreira MA, Bender D, Maller J, Sklar P, de Bakker PI, Daly MJ, Sham PC: PLINK: a tool set for whole-genome association and population-based linkage analyses. Am J Hum Genet 2007, 81:559-575.

17. Bioconductor Project [www.R-project.org]

18. Price AL, Patterson NJ, Plenge RM, Weinblatt ME, Shadick NA, Reich D: Principal components analysis corrects for stratification in genome-wide association studies. Nat Genet 2006, 38:904-909.

19. Dilthey AT, Moutsianas L, Leslie S, McVean G: HLA*IMP-an integrated framework for imputing classical HLA alleles from SNP genotypes. Bioinformatics 2011, 27:968-972.

20. Leslie S, Donnelly P, McVean G: A statistical method for predicting classical HLA alleles from SNP data. Am J Hum Genet 2008, 82:48-56.

21. Sawcer S, Hellenthal G, Pirinen M, Spencer CC, Patsopoulos NA, Moutsianas L Dilthey A, Su Z, Freeman C, Hunt SE, Edkins S, Gray E, Booth DR, Potter SC, Goris A, Band G, Oturai AB, Strange A, Saarela J, Bellenguez C, Fontaine B, Gillman M, Hemmer B, Gwilliam R, Zipp F, Jayakumar A, Martin R, Leslie S, Hawkins S, Giannoulatou E, et al: Genetic risk and a primary role for cell-mediated immune mechanisms in multiple sclerosis. Nature 2011, 476:214-219.

22. Li J, Ji L: Adjusting multiple testing in multilocus analyses using the eigenvalues of a correlation matrix. Heredity 2005, 95:221-227.

23. Nyholt DR: A simple correction for multiple testing for single-nucleotide polymorphisms in linkage disequilibrium with each other. Am J Hum Genet 2004, 74:765-769.

24. Howie B, Fuchsberger C, Stephens M, Marchini J, Abecasis GR: Fast and accurate genotype imputation in genome-wide association studies through pre-phasing. Nat Genet 2012, 44:955-959.

25. Willer CJ, Li Y, Abecasis GR: METAL: fast and efficient meta-analysis of genomewide association scans. Bioinformatics 2010, 26:2190-2191.
26. Purcell S, Cherny SS, Sham PC: Genetic power calculator: design of linkage and association genetic mapping studies of complex traits. Bioinformatics 2003, 19:149-150.

27. Allanore Y, Saad M, Dieude P, Avouac J, Distler JH, Amouyel P, MatucciCerinic M, Riemekasten G, Airo P, Melchers I, Hachulla E, Cusi D, Wichmann HE, Wipff J, Lambert JC, Hunzelmann N, Tiev K, Caramaschi P, Diot E, Kowal-Bielecka O, Valentini G, Mouthon L, Czirjak L, Damjanov N, Salvi E, Conti C, Muller M, Muller-Ladner U, Riccieri V, Ruiz B, et al: Genome-wide scan identifies TNIP1, PSORS1C1, and RHOB as novel risk loci for systemic sclerosis. PLoS Genet 2011, 7:e1002091.

28. Beretta L, Rueda B, Marchini M, Santaniello A, Simeon CP, Fonollosa V, Caronni M, Rios-Fernandez R, Carreira P, Rodriguez-Rodriguez L, Moreno A, Lopez-Nevot MA, Escalera A, Gonzalez-Escribano MF, Martin J, Scorza R: Analysis of class II human leucocyte antigens in Italian and Spanish systemic sclerosis. Rheumatology (Oxford) 2012, 51:52-59.

29. Harley JB, Alarcon-Riquelme ME, Criswell LA, Jacob CO, Kimberly RP, Moser KL, Tsao BP, Vyse TJ, Langefeld CD, Nath SK, Guthridge JM, Cobb BL, Mirel DB, Marion MC, Williams AH, Divers J, Wang W, Frank SG, Namjou B, Gabriel SB, Lee AT, Gregersen PK, Behrens TW, Taylor KE, Fernando M, Zidovetzki R, Gaffney PM, Edberg JC, Rioux JD, Ojwang JO, et al: Genomewide association scan in women with systemic lupus erythematosus identifies susceptibility variants in ITGAM, PXK, KIAA1542 and other loci. Nat Genet 2008, 40:204-210.

30. Ng PC, Henikoff S: SIFT: Predicting amino acid changes that affect protein function. Nucleic Acids Res 2003, 31:3812-3814.

31. Chun S, Fay JC: Identification of deleterious mutations within three human genomes. Genome Res 2009, 19:1553-1561.

32. Gateva V, Sandling JK, Hom G, Taylor KE, Chung SA, Sun X, Ortmann W, Kosoy R, Ferreira RC, Nordmark G, Gunnarsson I, Svenungsson E, Padyukov L, Sturfelt G, Jonsen A, Bengtsson AA, Rantapaa-Dahlqvist S, Baechler EC, Brown EE, Alarcon GS, Edberg JC, Ramsey-Goldman R, McGwin G Jr, Reveille JD, Vila LM, Kimberly RP, Manzi S, Petri MA, Lee A, Gregersen PK: A large-scale replication study identifies TNIP1, PRDM1, JAZF1, UHRF1BP1 and IL10 as risk loci for systemic lupus erythematosus. Nat Genet 2009, 41:1228-1233.

33. Al-Mayouf SM, Sunker A, Abdwani R, Abrawi SA, Almurshedi F, Alhashmi N, Al Sonbul A, Sewairi W, Qari A, Abdallah E, Al-Owain M, Al Motywee S, Al-Rayes H, Hashem M, Khalak H, Al-Jebali L, Alkuraya FS: Loss-of-function variant in DNASE1L3 causes a familial form of systemic lupus erythematosus. Nat Genet 2011, 43:1186-1188.

34. Mayes MD, Bossini-Castillo L, Gorlova O, Martin JE, Zhou X, Chen WV Assassi S, Ying J, Tan FK, Arnett FC, Reveille JD, Guerra S, Teruel M, Carmona FD, Gregersen PK, Lee AT, Lopez-Isac E, Ochoa E, Carreira P, Simeon CP, Castellvi I, Gonzalez-Gay MA, Spanish Scleroderma G, Zhernakova A, Padyukov L, Alarcon-Riquelme M, Wijmenga C, Brown M, Beretta L, Riemekasten $G$, et al: Immunochip analysis identifies multiple susceptibility loci for systemic sclerosis. Am J Hum Genet 2014, 94:47-61.

35. Ueki M, Takeshita H, Fujihara J, lida R, Yuasa I, Kato H, Panduro A, Nakajima T, Kominato $Y$, Yasuda T: Caucasian-specific allele in non-synonymous single nucleotide polymorphisms of the gene encoding deoxyribonuclease H-like 3 , potentially relevant to autoimmunity, produces an inactive enzyme. Clin Chim Acta 2009, 407:20-24.

36. Gruschwitz MS, Hornstein OP, von Den DP: Correlation of soluble adhesion molecules in the peripheral blood of scleroderma patients with their in situ expression and with disease activity. Arthritis Rheum 1995, 38:184-189.

37. Pendergrass SA, Hayes E, Farina G, Lemaire R, Farber HW, Whitfield ML, Lafyatis R: Limited systemic sclerosis patients with pulmonary arterial hypertension show biomarkers of inflammation and vascular injury. PLoS One 2010, 5:e12106.

doi:10.1186/s13075-014-0438-8

Cite this article as: Zochling et al:: An Immunochip-based interrogation of scleroderma susceptibility variants identifies a novel association at DNASE1L3. Arthritis Research \& Therapy 2014 16:438. 